\title{
THE CORONARY ARTERIES IN HEARTS WITH DISCORDANT ATRIOVENTRICULAR CONNECTIONS
}

\author{
Roxane McKay, MD, FRCS, \\ $\mathrm{FRCSC}^{\mathrm{a}}$ \\ Robert H. Anderson, BSc, MD, \\ FRCPath $^{\mathrm{b} *}$ \\ Audrey Smith, PhD, FIBMS
}

\begin{abstract}
Gross morphologic study of 14 hearts with congenitally corrected transposition or discordant atrioventricular connections and double-outlet right ventricle or pulmonary atresia disclosed consistently the origins of the coronary arteries from two aortic sinuses. With usual atrial arrangement, the artery arising in sinus 1 (right-hand facing), as seen from the noncoronary aortic sinus, supplied the morphologically right ventricle. Coronary blood supply to the morphologically left ventricle usually came from sinus 2 (left-hand facing), although in two hearts the circumflex branch was a continuation of the artery from sinus 1 . The sinus nodal artery arose from the circumflex coronary artery, and histologic studies of two hearts demonstrated that blood supply to the anterior atrioventricular node also came from this vessel. Early branching and entrapment in fat or right ventricular muscle, as well as malalignment of aortic and pulmonary sinuses, occurred frequently. These findings may have implications for coronary arterial transfer in the double switch operation in hearts with discordant atrioventricular connections. (J Thorac Cardiovasc Surg 1996; 111:988-97)
\end{abstract}

W ith the advent of combined atrial and arterial switch procedures for repair of congenitally corrected transposition, ${ }^{1-3}$ knowledge of the coronary arterial anatomy in this malformation will assume increasing surgical importance. Previous anatomic $^{4,5}$ and angiographic ${ }^{6}$ studies have characterized the origin and distribution of the major coro-

From the Institute of Child Health, Alder Hey Children's Hospital, Liverpool, England; the Department of Surgery, University of Saskatchewan, Saskatoon, Saskatchewan, Canada; the Division of Cardiovascular and Thoracic Surgery, ${ }^{a}$ University of Saskatchewan, Royal University Hospital, Saskatoon; the Department of Pediatrics, ${ }^{\text {b }}$ National Heart and Lung Institute, Royal Brompton Hospital, London, England; and the Institute of Child Health ${ }_{2}^{c}$ University of Liverpool, Royal Liverpool Children's Hospital Alder Hey, Liverpool, England.

Supported in part by the British Heart Foundation and the Joseph Levy Trust (R.H.A.) and by the Endowment Fund of The Royal Liverpool Children's Hospital (A.S.).

Received for publication March 9, 1995; accepted for publication July 27,1995

Address for reprints: A. Smith, PhD, FIBMS, Department of Anatomy, Institute of Child Health, Royal Liverpool Children's Hospital Alder Hey, Eaton Road, Liverpool, L12 2AP, England.

*Visiting Professor at the Institute of Child Health, Royal Liverpool Children's Hospital Alder Hey.

Copyright (C) 1996 by Mosby-Year Book, Inc.

$0022-5223 / 96 \$ 5.00+0 \quad \mathbf{1 2} / \mathbf{1} / \mathbf{6 8 3 9 2}$ nary vessels, but detailed description of morphologic features that are relevant to transfer of the coronary arteries is not readily available. Moreover, the terms that have been applied to the coronary arteries in congenitally corrected transposition become cumbersome and confusing in clinical practice. To address these deficiencies, we have examined hearts with discordant atrioventricular connections in the autopsy collections of the Institute of Child Health, University of Liverpool, and the University of Saskatchewan.

\section{Material and methods}

Fourteen hearts with discordant atrioventricular connections and discordant ventriculoarterial connections, single outlet of the heart (pulmonary atresia), or doubleoutlet right ventricle were examined from patients whose ages ranged from 3 weeks to 17 years at the time of death. A variety of surgical procedures that did not involve the coronary arteries had been done in the 10 oldest patients. Atrial arrangement was established according to morphologic criteria. ${ }^{7}$ In the nine specimens with attached lungs, ventricular rotation was estimated from the position of the cardiac apex. The spatial relationships of the great arteries, the size of the ventricles, and the types of associated defects were noted.

The patterns of the major coronary arteries were elucidated by blunt and sharp dissection and each artery was followed from its aortic origin to at least one major branch and, in all cases, beyond the origin of the sinus nodal artery. The position and number of coronary arterial orifices in each aortic sinus were noted, as were the 


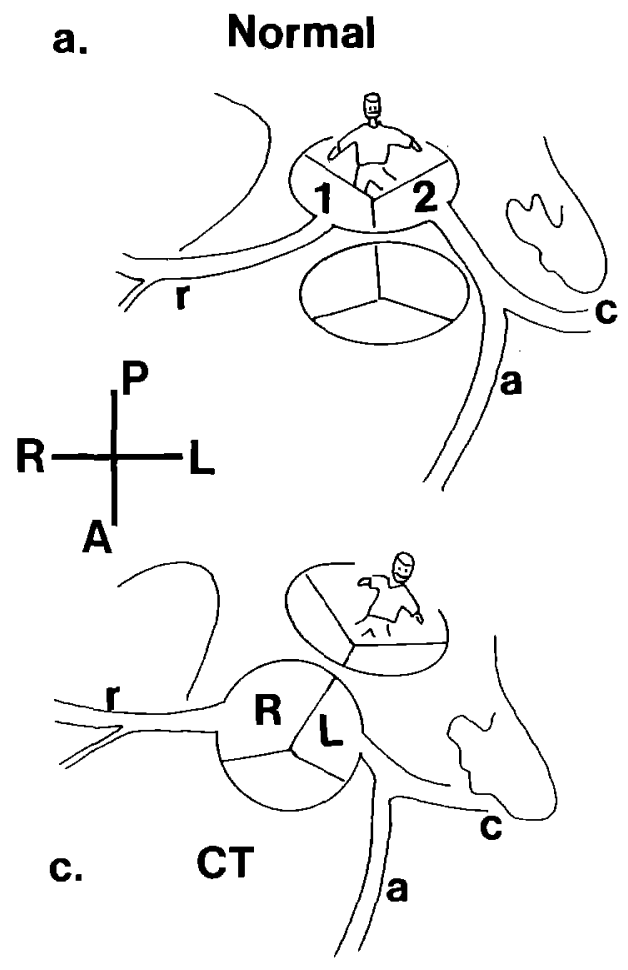

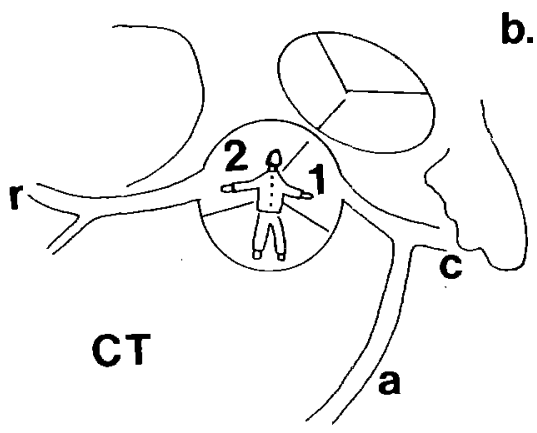

\section{CCTGA}

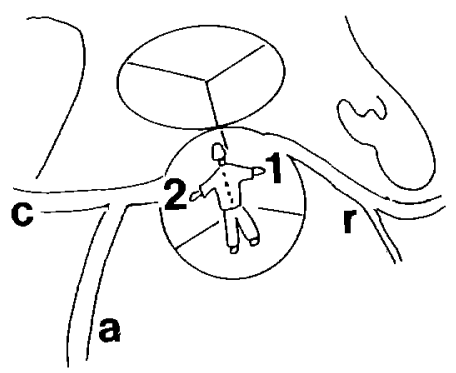

d.

Fig. 1. Problems in describing sinusal origins of coronary arteries are encapsulated in these cartoons. Usual arrangement in normal heart (a). Observer positioned in nonfacing sinus of aorta, looking toward pulmonary trunk, has morphologically right coronary artery arising from right-hand sinus (No. 1 in Leiden convention) and morphologically left coronary artery from left-hand sinus (No. 2). In complete transposition, situation is complicated because with most common arrangement (b), when viewed from aorta, the morphologically right coronary artery arises from sinus (No. 2). This is now to observer's left hand. For complete transposition, concordance between handedness of sinuses and arterial origin can be restored by viewing facing sinuses from a stance in pulmonary trunk (c). To retain this harmonious arrangement when dealing with congenitally corrected transposition it is necessary for observer to take up a position once more in nonfacing aortic sinus (d). This arrangement also holds good for cases with sinusal and commissural mismatch. $A$, Anterior; $L$, left; $P$, posterior; $R$, right; $r$, right coronary artery; $a$, anterior interventricular artery; $c$, circumflex artery; $C C T G A$, congenitally corrected transposition; $C T$, complete transposition.

distances between major branches and the depth of vessels within the epicardial fat or myocardium. It was possible in 10 hearts to determine the degree of alignment or malalignment between commissures and sinuses of the aortic and pulmonary trunks.

Three additional specimens that had been sectioned by our previously published method ${ }^{8}$ for study of the specialized conduction system in corrected transposition ${ }^{9}$ were examined for the course of the artery that supplied the atrioventricular node. The proximal coronary arterial patterns in these hearts, however, could not be assessed.

Terminology. In congenitally corrected transposition with usual atrial arrangement, the coronary arteries are mirror-imaged and appropriate to their ventricles. ${ }^{4,6} \mathrm{~A}$ precise and surgically useful terminology to account for their sinusal origins evolves logically from concepts re- cently elaborated for coronary arterial patterns in complete transposition. ${ }^{10-12}$

In both complete and congenitally corrected transposition, two of the three aortic sinuses almost always lie opposite sinuses of the pulmonary trunk and can thus be designated the facing or adjacent sinuses. In the view of a surgeon placed within the third, nonfacing sinus and looking toward the pulmonary trunk, one of the facing sinuses will fall under the right hand and the other under the left (Fig. 1, $a$ and $b$ ). ${ }^{12}$ The aortic sinuses, therefore, have been called right-hand facing and left-hand facing. ${ }^{11}$

On the basis of their morphology in the normal heart, the coronary arteries themselves are called right and left according to the predominant ventricular mass that they perfuse. Because the "handed" convention in complete transposition ${ }^{10-12}$ causes the artery arising from the right- 


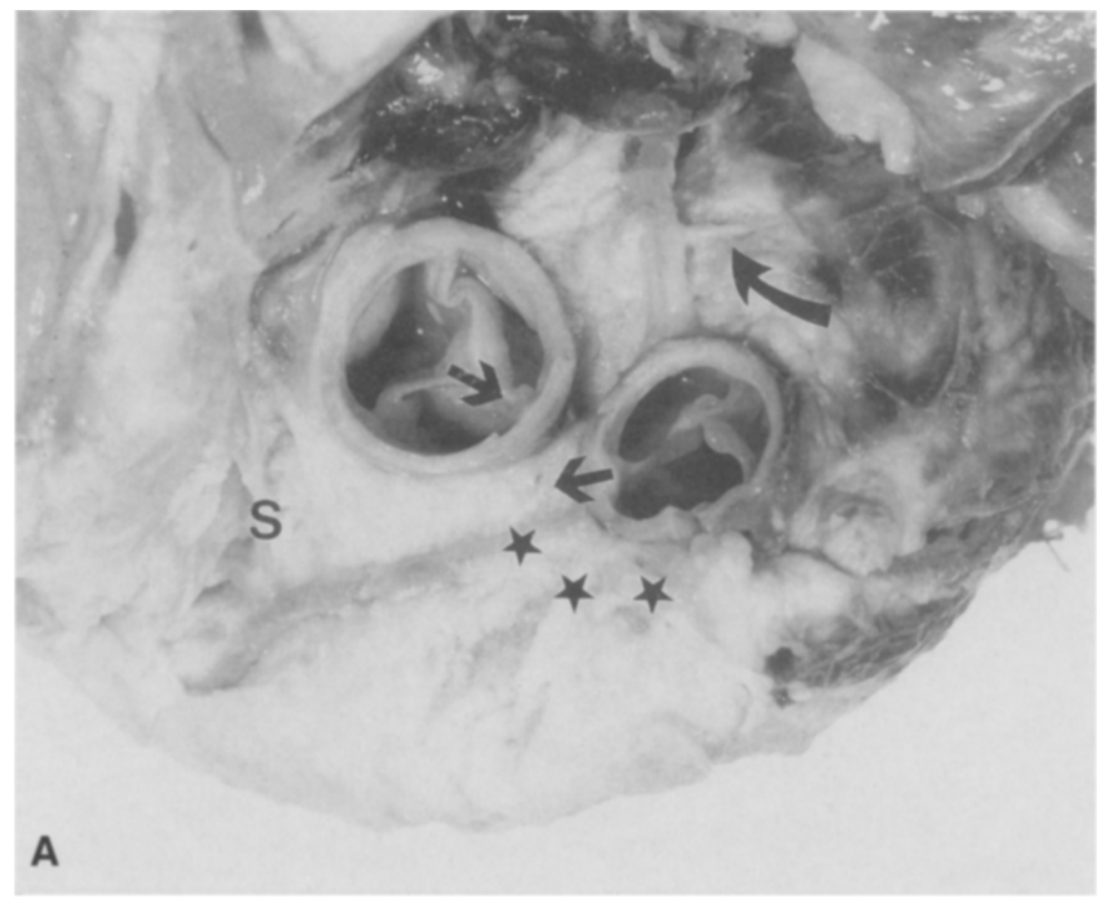

\section{cctga}
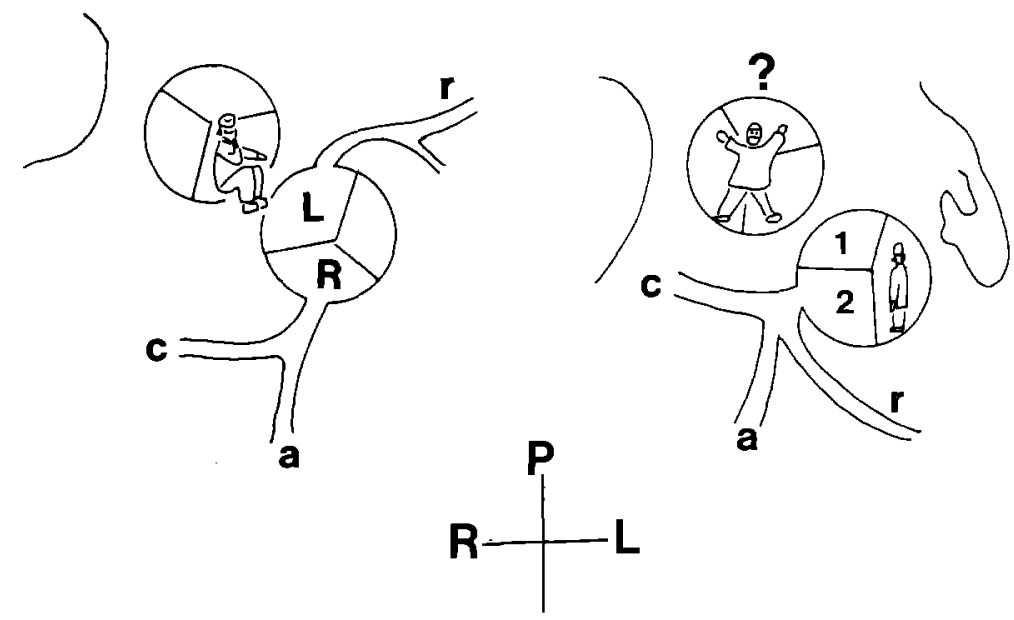

B

A

Fig. 2. A, View from top of heart with congenitally corrected transposition after transection of aorta and pulmonary trunk. Commissure between coronary arterial sinuses is poorly aligned (arrows). There is trifurcation of morphologically left coronary artery immediately after its origin (asterisks), and morphologically right coronary artery gives off large infundibular branch (curved arrow). B, Dilemma for classifying sinuses is illustrated in cases in which interostial commissure is poorly aligned and further compounded in presence of single sinusal origin (see text). $A, L, P, R$, Anterior, left, posterior, right; $L$, left-hand facing sinus from pulmonary trunk; $R$, right-hand facing sinus from pulmonary trunk; $S$, sinus nodal artery; cctga, congenitally corrected transposition; $a$, anterior interventricular artery; $c$, circumflex artery; $r$, right coronary artery. 

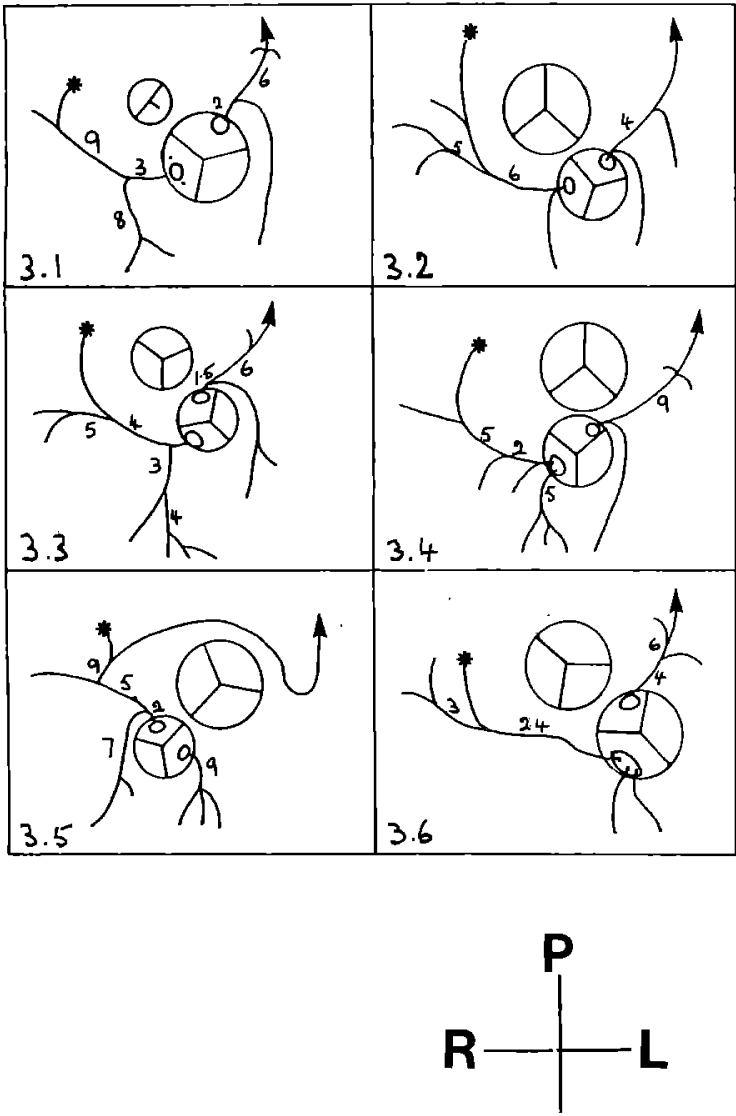

A

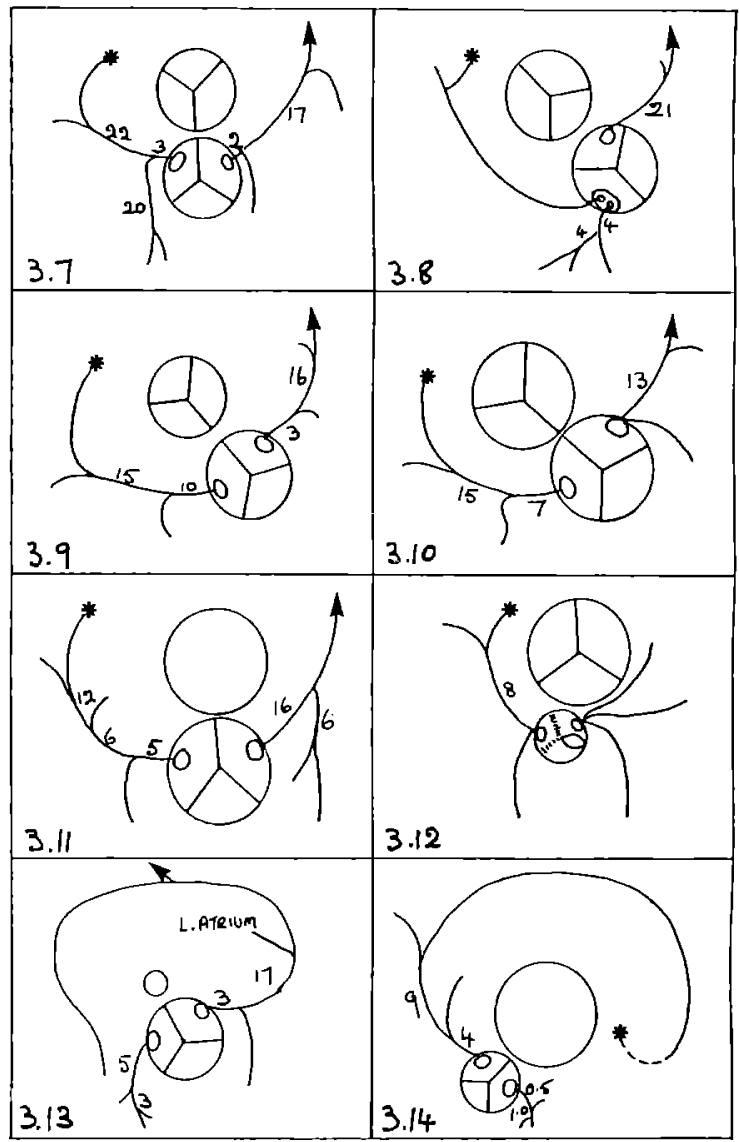

Fig. 3. Origins and branching patterns of coronary arteries in discordant atrioventricular connections. Boxes 3.1 to 3.13 represent specimens with usual atrial arrangement. Box 3.14 represents specimen with mirror-imaged atrial arrangement. Numbers indicate distances between branching points in millimeters. Asterisk indicates direction of sinus nodal artery. Arrow indicates continuation as posterior interventricular artery. $A, L, P, R$, Anterior, left, posterior, right.

hand sinus to be the morphologically left coronary artery and that from the left-hand sinus the morphologically right coronary artery, Sim and colleagues ${ }^{13}$ and Amato, Zelen, and Bushang ${ }^{14}$ proposed transfer of the observer to the pulmonary trunk (Fig. 1,c). By looking toward the aorta, the surgeon would then find the left hand usually pointing to the morphologically left coronary artery and the right hand indicating the morphologically right coronary artery. In congenitally corrected transposition, however, the coronary arterial origins are similar to those in the normal heart (compare Fig. 1, $a$, and Fig. 1, $d$ ), and only if the surgeon stands in the aortic nonfacing sinus will the appropriate hand fall on the right or left coronary artery.

This semantic problem of concordance or discordance is avoided completely by use of the Leiden classification, in which the right-hand facing sinus (seen from the aorta) is called sinus 1 and the left-hand facing sinus sinus $2 .^{11}$ These sinuses then retain their identity irrespective of whether they are viewed from the aorta or pulmonary trunk and regardless of the positions of spatial relationships of the great arteries, commissural mismatch (Fig. 2, $a$ and $b$ ), or mirror-imaged atrial arrangement. We have chosen, therefore, to view the coronary arterial orifices as from the nonfacing sinus of the aortic valve, designating the right-hand sinus sinus 1 and the left-hand sinus sinus 2 . In hearts with usual atrial arrangement, this will also cause the morphologically right and left coronary arteries to lie under the right and left hands of the observer, respectively.

\section{Results}

Thirteen hearts had usual (solitus) atrial arrangement, whereas one had mirror-imaged (inverted) atrial chambers. In usual atrial arrangement, the position of the aorta relative to the pulmonary trunk ranged from left anterior to right anterior, and in the solitary mirror-imaged case it was right anterior 


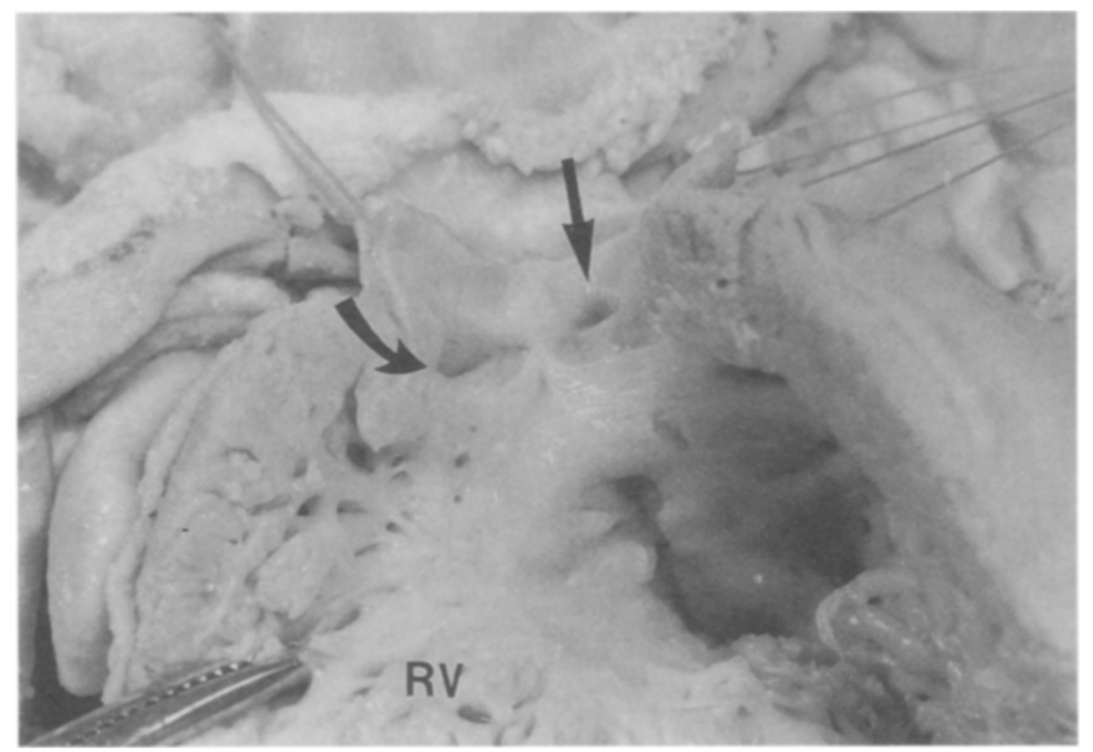

Fig. 4. Viewed from nonfacing aortic sinus, morphologically right coronary artery arises above sinutubular junction in sinus 1 (straight arrow). Morphologically left coronary artery lies within sinus 2 (curved arrow). RV, right ventricle.

Table I. Heart specimens

\begin{tabular}{|c|c|c|c|c|c|c|}
\hline $\begin{array}{l}\text { Specimen } \\
\quad \text { No. }\end{array}$ & $\begin{array}{l}\text { Age at } \\
\text { death }\end{array}$ & $\begin{array}{l}\text { Atrial } \\
\text { arrangement }\end{array}$ & $\begin{array}{l}\text { Ventriculoarterial } \\
\text { connections }\end{array}$ & $\begin{array}{l}\text { Position } \\
\text { of apex }\end{array}$ & $\begin{array}{l}\text { Position of aorta } \\
\text { relative to } P A\end{array}$ & Associated anomalies \\
\hline 1 & $3 \mathrm{wk}$ & Usual & Discordant & Left & Left anterior & $\begin{array}{l}\text { VSD (large, muscular); subpulmonary } \\
\text { muscle bar }\end{array}$ \\
\hline 2 & $3 w k$ & Usual & Discordant & Right & Left anterior & None \\
\hline 3 & $3 \mathrm{wk}$ & Usual & Discordant & Left & Left anterior & PAD \\
\hline 4 & $3 \mathrm{wk}$ & Usual & Discordant & Middle & Anterior & $\begin{array}{l}\text { VSD (subpulmonary); ASD; subpulmonary } \\
\text { stenosis (accessory mitral valve tissue) }\end{array}$ \\
\hline 5 & $1 \mathrm{yr}, 5 \mathrm{mo}$ & Usual & Discordant & Middle & Right anterior & VSD (perimembranous); coarctation \\
\hline 6 & 3 yr & Usual & Discordant & Middle & Left anterior & $\begin{array}{l}\text { VSD (perimembranous); subpulmonary } \\
\text { muscle bar; Epstein LSAVV }\end{array}$ \\
\hline 7 & $3 \mathrm{yr}, 6 \mathrm{mo}$ & Usual & Discordant & Middle & Anterior & VSD (muscular); straddling LSAVV \\
\hline 8 & $6 \mathrm{yr}$ & Usual & Discordant & Right & Left anterior & $\begin{array}{l}\text { VSD (perimembranous); accessory mitral } \\
\text { valve tissue }\end{array}$ \\
\hline 9 & $10 \mathrm{yr}$ & Usual & Discordant & - & Left anterior & VSD (muscular); coarctation \\
\hline 10 & $16 \mathrm{yr}$ & Usual & Discordant & - & Left anterior & $\begin{array}{l}\text { VSD (perimembranous); } \\
\text { ASD; Ebstein LSAVV }\end{array}$ \\
\hline 11 & $17 \mathrm{yr}, 3 \mathrm{mo}$ & Usual & Discordant & - & Anterior & $\begin{array}{l}\text { VSD (doubly committed subarterial); } \\
\text { pulmonary stenosis }\end{array}$ \\
\hline 12 & $1 \mathrm{wk}$ & Usual & DORV & - & Anterior & $\begin{array}{l}\text { AS; VSD (perimembranous); small RV; } \\
\text { subaortic muscular obstruction }\end{array}$ \\
\hline 13 & $9 \mathrm{yr}$ & Usual & Discordant & - & Left anterior & VSD (perimembranous); pulmonary atresia \\
\hline 14 & $3 \mathrm{yr}, 3 \mathrm{mo}$ & Mirror-imaged & Discordant & Right & Right anterior & $\begin{array}{l}\text { VSD (multiple muscular and perimembranous); } \\
\text { Epstein RSAVV;ASD; valvular } \\
\text { and subvalvular PS }\end{array}$ \\
\hline
\end{tabular}

$A S$, Aortic stenosis; $A S D$, atrial septal defect; $D O R V$, double-outlet right ventricle; $L S A V V$, left-sided atrioventricular valve (tricuspid); $P A$, pulmonary artery; $P A D$, patent arterial duct; $P S$, pulmonary stenosis; $R S A V V$, right-sided atrioventricular valve (tricuspid); $R V$, right ventricle; $V S D$, ventricular septal defect.

(Fig. 3). The cardiac apex lay slightly toward the right in three hearts, slightly toward the left in two, and assumed a midposition in four. There was no instance of complete apicocaval juxtaposition, ${ }^{1}$ and the spatial relations of the great arteries did not correspond with the position of the ventricles. ${ }^{15}$ Most hearts had several associated anomalies (Table I).

In all specimens, coronary arterial orifices were 


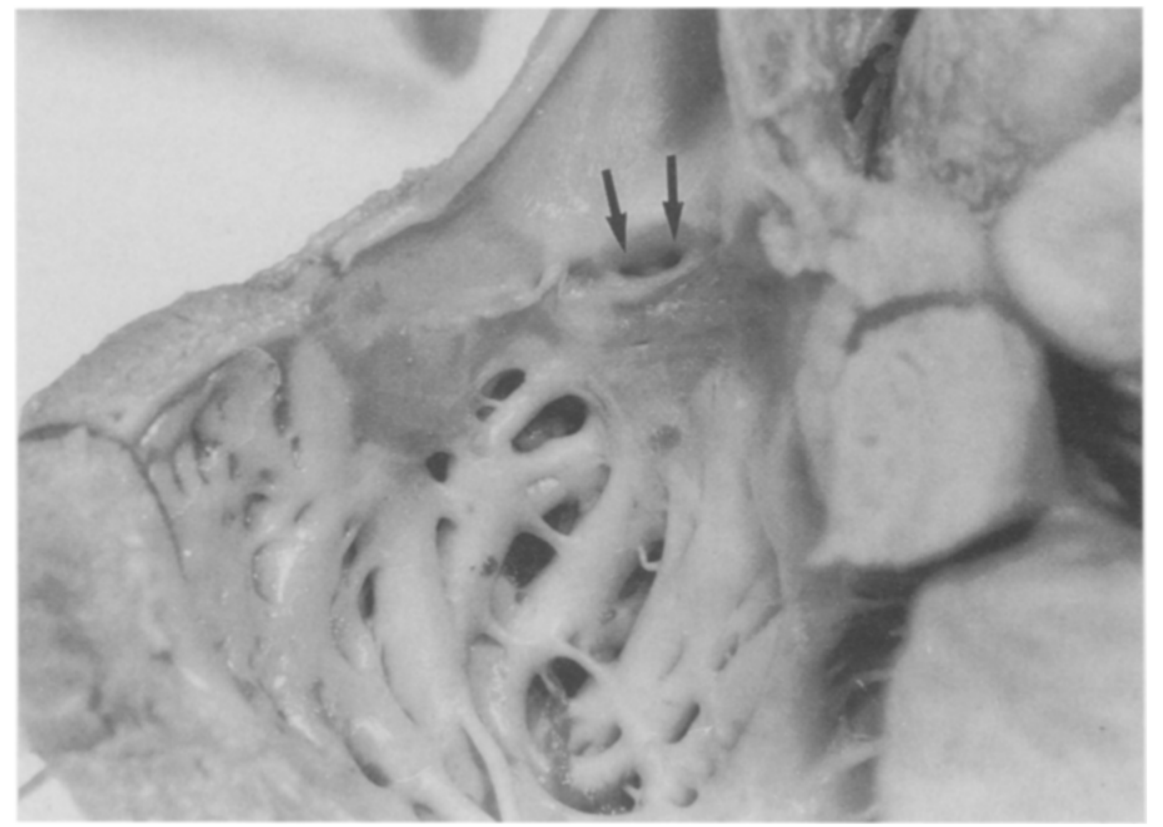

Fig. 5. Early division of morphologically left coronary artery results in two secondary orifices within coronary arterial orifice (arrows). Note extension of aortic valvular leaflet onto right ventricular muscular trabeculation (see also Fig. 8).

present in both sinuses 1 and 2 (Fig. 3). With usual atrial arrangement, the anterior interventricular and circumflex arteries supplying the morphologically left ventricle usually arose from sinus 2, either directly or through an unbranched segment of variable length. The sinus nodal artery originated as a branch of the circumflex artery in all 12 hearts in which it could be identified positively. With usual atrial arrangement, the artery arising from sinus 1 always supplied the morphologically right ventricle. This generally gave off an infundibular branch soon after its origin and continued in the atrioventricular groove to end as the posterior interventricular artery. In one heart (No. 5), however, with right anterior aorta, the posterior interventricular artery came from the circumflex artery, which supplied the morphologically left ventricle, having passed behind the pulmonary trunk. In this heart, the artery that arose from sinus 1 was an isolated infundibular artery to the morphologically right ventricle. In two other hearts, one with usual atrial arrangement (No. 13) and the one with mirror-imaged atria (No. 14), the circumflex artery was the continuation of the morphologically right coronary artery, having crossed the crux to continue in the atrioventricular groove between morphologically right atrium and left ventricle. Although the sinus nodal artery could not be identified in either of these specimens, it is likely by exclusion that it still arose from the circumflex artery at its distal end.

When there was good commissural alignment (nine hearts), the coronary arterial orifices generally lay in the midportion of each aortic sinus. In the five remaining hearts, the aorta and pulmonary trunk were both rotated, such that sinus 1 (right-hand facing) came to lie directly adjacent to a sinus of the pulmonary trunk (Figs. 2 and 3). In these specimens, the origin of the coronary artery in sinus 1 lay more toward its commissure with the noncoronary sinus, although in no case did it extend to the hinge point of the aortic leaflet. ${ }^{16}$ In only one heart was the morphologically right coronary artery found arising above the sinotubular junction (Fig. 4). Multiple orifices were identified in sinus 2 (left-hand facing) of three specimens with usual atrial arrangement (Fig. 3). This was the extreme end of a spectrum of early branching patterns for both the morphologically left and right coronary arteries, and it was frequently possible to observe arterial wall between major branches within the coronary arterial orifice itself (Fig. 5).

Externally, and in striking contrast with complete transposition, both the origins and proximal extensions of all coronary arteries were closely applied to 


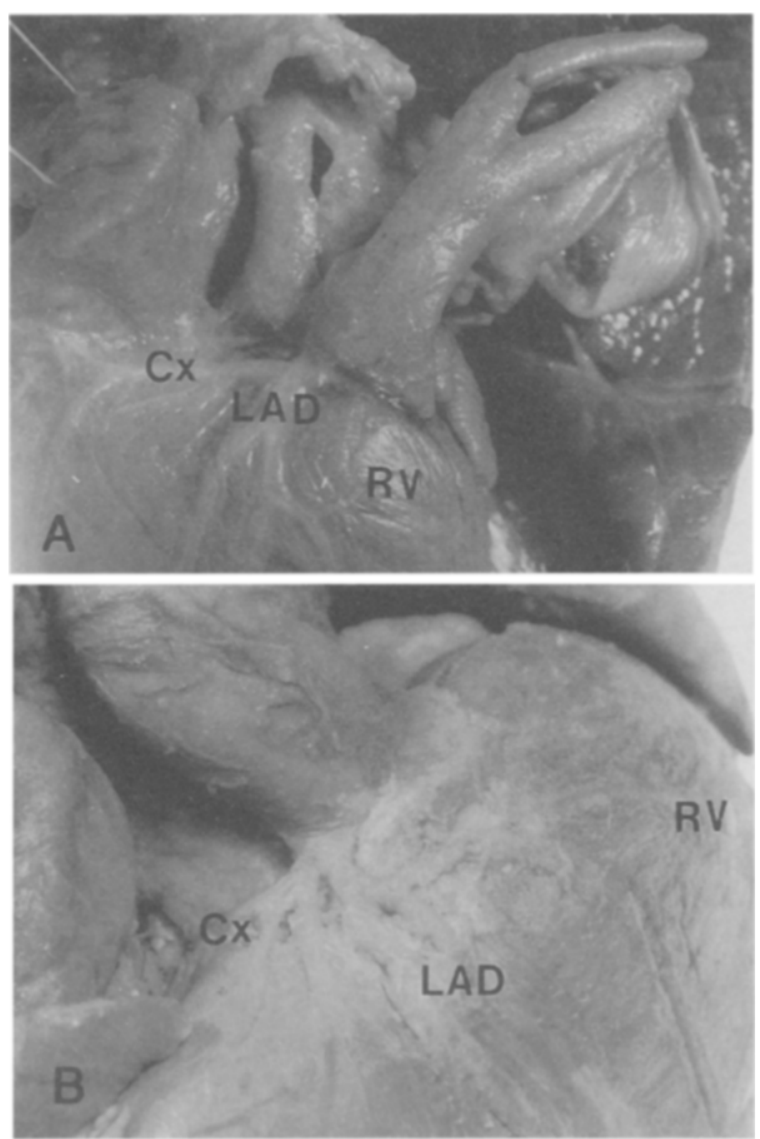

Fig. 6. A, Left ventricular coronary artery in 3-week old patient. B, Left ventricular coronary artery in 3-month old patient. In each specimen there are a large anterior interventricular branch, circumflex branch, and smaller branches to right ventricular free wall. $C x$, Circumflex artery; $L A D$, left anterior descending (interventricular) artery; $R V$, right ventricular wall.

the surface of the morphologically right ventricle. In the younger hearts, the coronary arterial branches could be observed beneath a thin layer of epicardium (Fig. 6, $A$ ), but with advanced age the branches became deeply imbedded in fat (Fig. 6, B). This occurred despite the normal position of the coronary orifices within the aortic sinus, as if the right ventricular infundibulum had grown distally to engulf the ventriculoarterial junction. The large first infundibular branch of the morphologically right coronary artery ran a frankly intramyocardial course soon after its origin in two specimens (Fig. 7, $A, B$, and $C$ ).

An incidental finding in two hearts was a windsock extension of the aortic leaflet in sinus 2 down onto a right ventricular trabeculation (Figs. 5 and 8).
This produced a funnel-like sinus that was considerably deeper than the adjacent sinuses and that predominantly contained muscle in its base. The valve, however, was competent, with good coaptation among three pliable leaflets. A stenotic, unicommissural aortic valve was present within a threesinus aortic root $^{17}$ in one neonatal specimen (No. 12) with double-outlet right ventricle.

In two additional specimens that had been sectioned previously for a study of the specialized conduction system, ${ }^{9}$ the course of the artery that supplied the compact portion of the connecting anterior atrioventricular node was traced to the circumflex branch of the morphologically left coronary artery. In both cases it branched from an artery that continued intramyocardially into the anterior wall of the right atrium. Because the more distal course of this artery was not included in the blocks of tissue for sectioning, it was not possible to establish its final destination.

\section{Discussion}

Compared with those in complete transposition, ${ }^{10,11,18,19}$ both the origins and the proximal branching patterns of the coronary arteries in congenitally corrected transposition appear to be more consistent. Regardless of the spatial relationships of the great arteries or associated anomalies, the artery arising in sinus 1 supplied the morphologically right ventricle in all hearts with usual atrial arrangement. The anterior interventricular artery to the morphologically left ventricle consistently originated in sinus 2, either directly or from a left main stem. The circumflex coronary artery generally arose from sinus 2, either directly or as a branch of the morphologically left coronary artery, but in two hearts it was the termination of the morphologically right coronary artery. Only in one case did a proximal morphologically left coronary artery give off a significant branch to the morphologically right ventricle. Although single sinusal origin of all the coronary arteries has been reported in congenitally corrected transposition, ${ }^{6}$ it was not observed among our specimens. The origins and proximal branching patterns of the coronary arteries were thus favorable for an arterial switch procedure in all hearts examined.

With regard to translocation of the coronary arterial orifices to the neo-aorta, however, several other morphologic features may have important technical implications. The length of the unbranched morphologically left coronary artery (Fig. 3 ) was frequently only 2 to $3 \mathrm{~mm}$, and in many hearts 

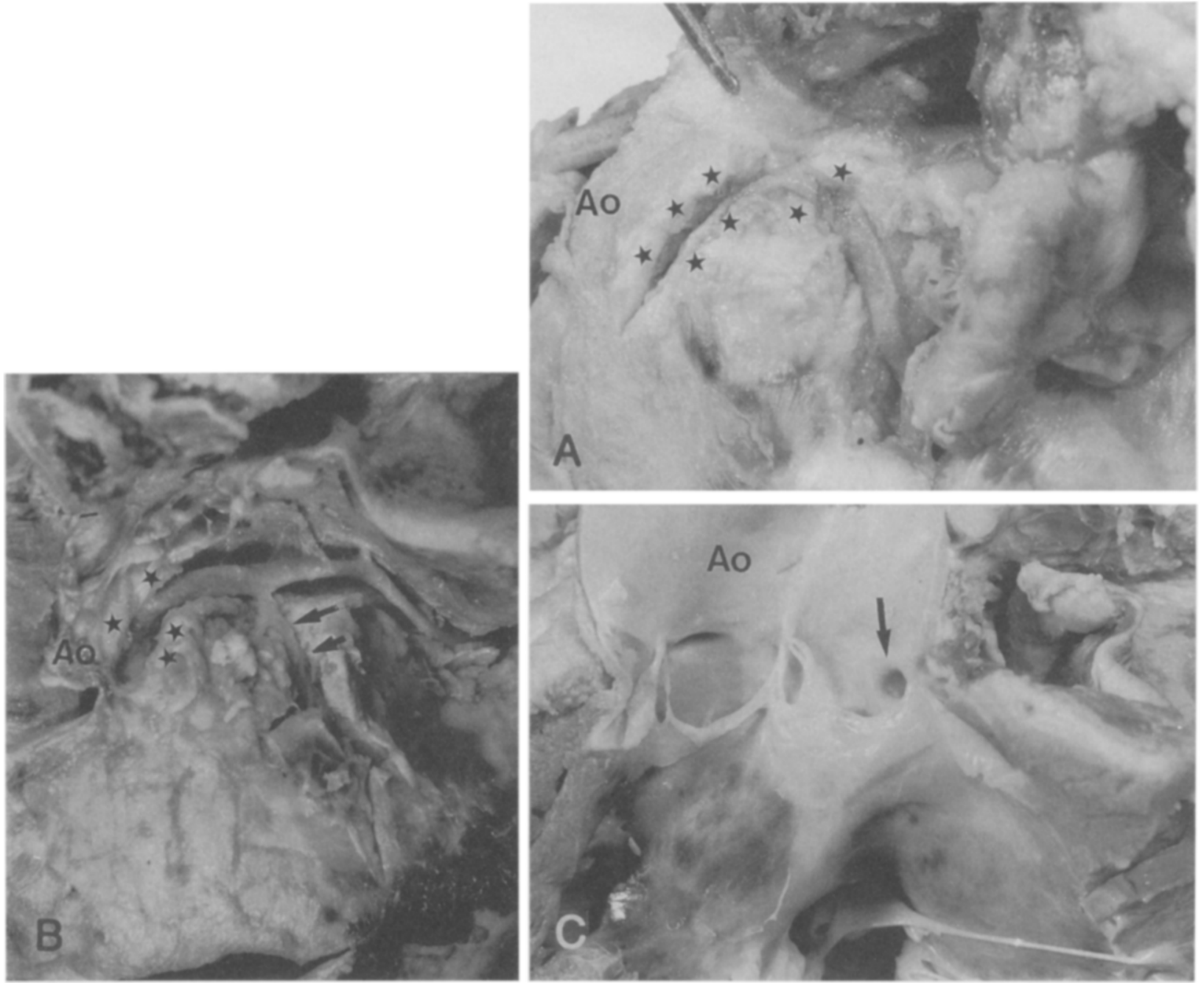

Fig. 7. A, Morphologically right coronary artery deeply imbedded in fat (asterisks). B, Proximal portion of morphologically right coronary artery imbedded in fat (asterisks) with intramyocardial branch (arrows). C, Internally, orifice of coronary artery illustrated in $\mathbf{B}$ has normal position within aortic sinus (arrow). Ao, Aorta.

the anterior interventricular artery arose virtually within the aortic sinus (Fig. 5). Although mobilization of the proximal branches, excision of a generous button of surrounding sinus, and use of a trapdoor technique $^{20}$ should permit successful transfer in most patients, it should be noted that heart block and systemic ventricular failure have been attributed to obstruction of this vessel in one early survivor of the double switch operation. ${ }^{1 .}$ Similarly, the close application of the proximal coronary arteries to the epicardium and, in some cases, an intramyocardial course may make identification of the proximal arteries difficult. ${ }^{21}$ More extensive dissection may be required to achieve sufficient mobility for transfer to the neo-aorta. In this respect, it was of interest that the younger patients, who would most likely require early operation because of heart failure from a large ventricular septal defect with or without atrioventricular valvular regurgitation, ${ }^{22}$ showed less epicardial fat and muscle around the proximal coronary arteries. They would thus be the more favorable candidates for a combined arterial and atrial switch. ${ }^{3}$ Malalignment of the commissures was not uncommon among this group of hearts. The pulmonary trunk, however, is deeply wedged into the left ventricular outflow tract in congenitally corrected transposition, ${ }^{4}$ such that the coronary arterial orifices are generally implanted above the sinus into 


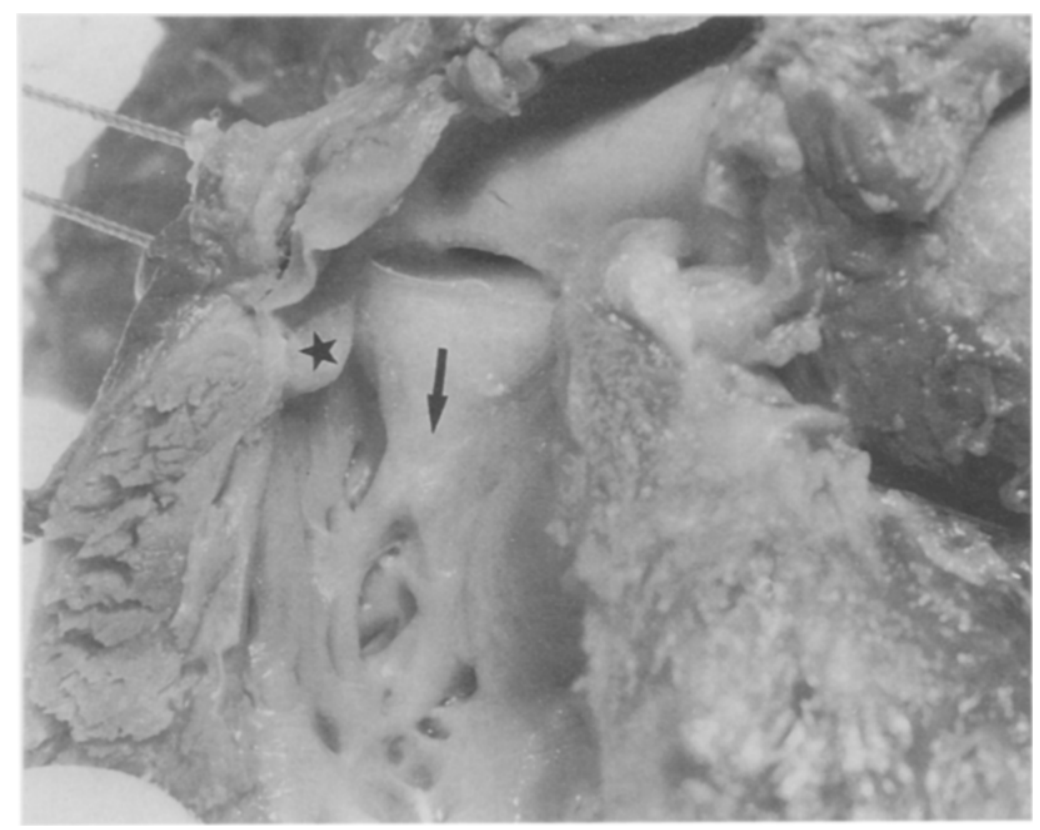

Fig. 8. Viewed from position of nonfacing sinus, aortic leaflet of sinus 2 extends downward within right ventricle (arrow), in contrast with normal attachments of leaflet tissue in other sinuses (asterisk indicates noncoronary sinus).

the arterial wall. $^{2}$ Commissural malalignment, therefore, should not complicate coronary arterial transfer.

It was an interesting finding that the artery supplying the anomalous anterior atrioventricular node in the two hearts studied histologically arose in conjunction with an atrial artery. In our own unpublished studies of the atrial arteries in 19 hearts with complete transposition and intact ventricular septum, we found nine cases in which arteries took origin from the anterior surface of the heart and supplied the anterior transitional cell zone of the normally positioned atrioventricular node. In four of these, the arteries to the transitional zone of the atrioventricular node arose in conjunction with the sinus nodal artery. Such an artery supplying this area was never conspicuous in a control series of 10 normal hearts. In the hearts with congenitally corrected transposition and usual atrial arrangement, the artery to the sinus node consistently arose on the front of the heart from the circumflex artery. It seems likely, therefore, that both the sinus node and the anterior atrioventricular node arteries receive their blood supply from branches of the morphologically left coronary artery that pass along the medial side of the morphologically right atrial wall. Al- though these branches arise sufficiently distal to make kinking during coronary translocation unlikely, they could be at risk for damage during construction of the Senning or Mustard pathways or repair of an atriotomy. ${ }^{20}$

We thank Ken Walters, Gwen Connell, Joanne Drury, and Sandra Longworth for their technical contributions to this paper.

\section{REFERENCES}

1. Yagihara T, Kishimoto $H$, Isobe $F$, et al. Double switch operation in cardiac anomalies with atrioventricular and ventriculoarterial discordance. J Thorac Cardiovasc Surg 1994;107:351-8.

2. Yamagishi M, Imai Y, Hoshino S, et al. Anatomic correction of atrioventricular discordance. J Thorac Cardiovasc Surg 1993;105:106-76.

3. Brawn WJ, Wright JG, Sethia B, de Giovanni J, Silove ED. Atrial and arterial switch repair for corrected transposition and ventricular septal defect with severe tricuspid valve regurgitation [Abstract]. Cardiol Young 1993;3(suppl 1):58.

4. Allwork SP, Bentall HH, Becker AE, et al. Congenitally corrected transposition of the great arteries: morphologic study of 32 cases. Am J Cardiol 1976;38:910-23.

5. Lev M, Rowlatt UF. Pathological anatomy of mixed levocardia: a review of thirteen cases of atrial or ventricular inversion with or without corrected transposition. Am J Cardiol $1961 ; 8: 216-63$. 
6. Dabizzi RP, Barletta GA, Caprioli G, Baldrighi G, Baldrighi V. Coronary anatomy in corrected transposition of the great arteries. J Am Coll Cardiol 1988;12:486-91.

7. Anderson RH, Macartney FJ, Shinebourne EA, Tynan MJ. Definitions of cardiac chambers. In: Anderson RH, Shinebourne EA, eds. Paediatric cardiology 1977. London: Churchill Livingstone, 1978:5-15.

8. Smith A, Ho SY, Anderson RH. Histological study of the cardiac conducting system as a routine procedure. Med Lab Sci 1977;34:223-9.

9. Anderson RH, Arnold R, Wilkinson JL. The conducting system in congenitally corrected transposition. Lancet 1973; 1:1286-8.

10. Smith A, Arnold R, Wilkinson JL, Hamilton DI, McKay R, Anderson RH. An anatomical study of the patterns of the coronary arteries and sinus nodal artery in complete transposition. Int J Cardiol 1986;12:295-304.

11. Gittenberger-de Groot A, Sauer U, Oppenheimer-Dekker A, Quaegebeur J. Coronary arterial anatomy in transposition of the great arteries: a morphologic study. Pediatr Cardiol 1983;4(suppl 1):15-24.

12. Anderson RH, Henry GW, Becker AE. Morphologic aspects of complete transposition. Cardiol Young 1991;1:41-53.

13. Sim EKW, van Son JAM, Edwards WD, Julsrud PR, Puga FJ. Coronary artery anatomy in complete transposition of the great arteries. Ann Thorac Surg 1994;57:890-4.

14. Amato JJ, Zelen J, Bushong J. Coronary arterial patterns in complete transposition: classification in relation to the arterial switch procedure. Cardiol Young 1994;4:329-39.

15. Attie F, Ovseyevitz J, Llamas G, Buendia A, Vangas J, Muñoz L. The clinical features and diagnosis of a discordant atrioventricular connexion. Int J Cardiol 1985;8:395-419.

16. Yacoub $\mathrm{MH}$, Radley-Smith R. Anatomy of the coronary arteries in transposition of the great arteries and methods for their transfer in anatomical correction. Thorax 1978;33:41824.

17. McKay R, Smith A, Leung MP, Arnold R, Anderson RH. Morphology of the ventriculoaortic junction in critical aortic stenosis. J Thorac Cardiovasc Surg 1992;104:434-42.

18. Shaher RM, Puddu GC. Coronary artery anatomy in complete transposition of the great vessels. Am J Cardiol 1966; 17:355-61.

19. Kurosawa H, Imai Y, Kawada M. Coronary arterial anatomy in regard to the arterial switch procedure. Cardiol Young 1991;1:54-62.

20. Mee R. The arterial switch operation. In: Stark J, de Leval M, eds. Surgery for congenital heart defects. 2nd ed. London: WB Saunders, 1994:483-500.

21. Anderson KR, McGoon DC, Lie JT. Vulnerability of coronary arteries in surgery for transposition of the great arteries. J Thorac Cardiovasc Surg 1978;76:135-9.

22. Lundstrom U, Bull C, Wyse RKH, Somerville J. The natural and "unnatural" history of congenitally corrected transposition. Am J Cardiol 1990;65:1222-9.

\section{Availability of Journal back issues}

As a service to our subscribers, copies of back issues of The Journal of Thoracic and Cardiovascular Surgery for the preceding 5 years are maintained and are available for purchase from the publisher, Mosby-Year Book, Inc., at a cost of $\$ 13.50$ per issue. The following quantity discounts are available: $25 \%$ off on quantities of 12 to 23 , and one third off on quantities of 24 or more. Please write to Mosby-Year Book, Inc., Subscription Services, 11830 Westline Industrial Drive, St. Louis MO 63146-3318, or call 800-453-4351 or 314-453-4351 for information on availability of particular issues. If unavailable from the publisher, photocopies of complete issues are available from University Microfilms International, 300 N. Zeeb Rd., Ann Arbor, MI 48106, 313-761-4700. 